Check for updates

Cite this: RSC Adv., 2018, 8, 23720

\title{
Ultrasensitive determination of ascorbic acid by using cobalt oxyhydroxide nanosheets to enhance the chemiluminescence of the luminol- $\mathrm{H}_{2} \mathrm{O}_{2}$ system $\dagger$
}

\begin{abstract}
Huihui Xu, ${ }^{a}$ Qiyong Cai, ${ }^{a}$ Qiuyu Nie, ${ }^{a}$ Zhun Qiao, ${ }^{a}$ Song Liu (D) *a and Zhaohui Li (D) *b
Ascorbic acid (AA) as an essential vitamin in the human body participates in various physiological reactions and plays a key role in many biochemical processes. Therefore, it is of vital importance to monitor and quantify AA in commercial tablets, beverages and food. In this work, a rapid and ultrasensitive chemiluminescence (CL) system for the detection of AA was developed, in which ultrathin cobalt oxyhydroxide $(\mathrm{CoOOH})$ nanosheets were applied in the conventional luminol $-\mathrm{H}_{2} \mathrm{O}_{2} \mathrm{CL}$ system. The results showed that ultrathin $\mathrm{CoOOH}$ nanosheets as a catalyzer remarkably improved the $\mathrm{CL}$ intensity of the $\mathrm{CoOOH}$-luminol- $\mathrm{H}_{2} \mathrm{O}_{2}$ system, up to about 1400 -fold. Under the optimized conditions, the $\mathrm{CL}$

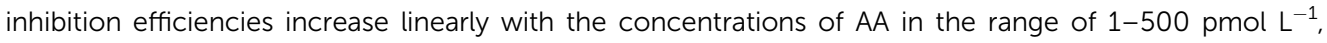
and the limit of detection was $39 \mathrm{fmol} \mathrm{L}^{-1}$. Moreover, the proposed $\mathrm{CL}$ system was successfully applied in the determination of $A A$ in medicinal tablets with satisfactory results.
\end{abstract}

Received 24th April 2018

Accepted 22nd June 2018

DOI: $10.1039 / \mathrm{c} 8 \mathrm{ra0} 3528 \mathrm{~h}$

rsc.li/rsc-advances determination of AA via the combination of a functionalized multi-walled carbon nanotube layer with a thin molecularly imprinted polymer (MIP) film. The integration of MIT in organic electrochemical transistor sensors (OECTs) is a reasonably effective route to improve the selectivity and applicability of OECTs in biosensors. ${ }^{15}$ Although these methods are highly sensitive, most of them suffer disadvantages such as expensive cost, time-consuming, a complicated pretreatment process and the operation of sophisticated instruments, which limit their wide applications. Compared with other methods, chemiluminescence (CL) sensors do not need an excitation source and the corresponding spectrometric systems. Many drawbacks of fluorescence sensors will be avoided including photobleaching and autofluorescence. These advantages of CL sensors greatly improve the sensitivity. Conventional and primary CL systems including luminol, acridinium ester, AMPPT, potassium permanganate and $\mathrm{Ce}(\mathrm{Iv})$ have got extensive development and applications. All these methods have been used for detecting AA such as luminol- $\mathrm{K}_{3} \mathrm{Fe}(\mathrm{CN})_{6}-\mathrm{GNPs},{ }^{16}$ cerium(Iv)-rhodamine B CL system, ${ }^{17}$ luminol- $\mathrm{H}_{2} \mathrm{O}_{2}$-gold colloids system, ${ }^{18}$ and $\mathrm{Mg}-\mathrm{Al}-\mathrm{CO}_{3}$ LDHs-catalyzed $\mathrm{ONOOH}$ system. ${ }^{19}$ The luminol- $\mathrm{H}_{2} \mathrm{O}_{2}$ system, as a popular and classic CL reaction, has been extensively investigated. It can be catalyzed by metal ions, nanoparticles, graphene oxide and peroxidases. However, there are still some shortcomings of these catalysts, such as high toxicity and cost for metal ions and metal nanoparticles, complicated synthetic steps for graphene oxide, and low stability for peroxidases. anstitute of Chemical Biology and Nanomedicine (ICBN), State Key Laboratory of Chemo/Biosensing and Chemometrics, College of Chemistry and Chemical Engineering, Hunan University, Changsha, 410082, P. R. China. E-mail: liusong@ hnu.edu.cn

${ }^{b}$ College of Chemistry and Molecular Engineering, Zhengzhou University, Zhengzhou 450001, P. R. China. E-mail: zhaohui.li@zzu.edu.cn

$\dagger$ Electronic supplementary information (ESI) available: Additional figures. See DOI: $10.1039 / \mathrm{c} 8 \mathrm{ra} 03528 \mathrm{~h}$ 
In recent years, cobalt oxyhydroxide $(\mathrm{CoOOH})$ nanosheets are known by its rich electrical and catalytic properties, ${ }^{20}$ which were explored in sensing of AA. For example, Li et al. developed a novel strategy on the basis of the specific reaction of $\mathrm{CoOOH}$ and AA for detection and imaging of AA in living cells and in vivo. ${ }^{21} \mathrm{CoOOH}$ nanoflakes can quench the luminescence of persistent luminescence nanoparticles (PLNPs), the presence of AA can reduce $\mathrm{CoOOH}$ into $\mathrm{Co}^{2+}$ and the luminescence was recovered. Recently, Cui et al. reported that under the weak acidic condition and in the absence of hydrogen peroxide, $\mathrm{CoOOH}$ nanosheets can catalyze the $3,3^{\prime}, 5,5^{\prime}$-tetramethylbenzidine (TMB) to produce blue solution which could reduce the fluorescence intensity of albumin-stabilized gold nanoclusters (BSA-AuNCs). The addition of ascorbic acid destroyed some of the $\mathrm{CoOOH}$ nanosheets and retarded the catalytic oxidation, in hence, less fluorescence was reduced. ${ }^{22}$ Yao's group proposed a novel label-free fluorescent sensing system to detect alkaline phosphatase (ALP) which can catalyze L-ascorbic acid-2phosphate into AA based on chemical redox strategy to modulate the fluorescence of nitrogen-doped graphene quantum dots (NGQDs). ${ }^{23}$ It is worthy to note that all these are turn-on fluorescence probes. ${ }^{24}$ However, the limited quenching capability of $\mathrm{CoOOH}$ nanosheets and the deficiency in fluorescence resonance energy transfer between $\mathrm{CoOOH}$ nanosheets and fluorescent materials led to the low sensitivity of these methods. In addition, in fluorescence detection an external light source is required.

In this work, the enhancing $\mathrm{CL}$ of luminol- $\mathrm{H}_{2} \mathrm{O}_{2}$ system was built for AA detection in the presence of $\mathrm{CoOOH}$ nanosheets. To the best of our knowledge, it is the first time that $\mathrm{CoOOH}$ nanosheets were applied in CL system. The prepared ultrasensitive $\mathrm{CoOOH}$ nanosheets exhibited excellent catalytic property on CL system. On the basis of the mechanism demonstrated in Scheme 1 the enhancing CL method for AA detection was developed. The results showed that $\mathrm{CoOOH}$ nanosheets have a remarkably enhancing effect on the CL of luminol- $\mathrm{H}_{2} \mathrm{O}_{2}$ system when its concentration is low. AA can reduce the $\mathrm{CoOOH}$ nanosheets to $\mathrm{Co}^{2+}$ and inhibit the $\mathrm{CL}$ of luminol- $\mathrm{H}_{2} \mathrm{O}_{2}$ enabling the ultrasensitive detection of AA with the limit of detection as $39 \mathrm{fmol} \mathrm{L}^{-1}$. This work provides an ultrasensitive, simple and rapid route to construct $\mathrm{CoOOH}-$ luminol- $\mathrm{H}_{2} \mathrm{O}_{2} \mathrm{CL}$ sensor, which has been successfully applied to the detection of AA in medicinal tablets with satisfactory results. Due to the fascinating properties of the modified CL system including ultrasensitive, simple, low consumption and easy to operate, it was anticipated that in the near future the method would has promising applications in sensitive detection of target analytes.

\section{Experimental procedures}

\section{Reagents and materials}

Ascorbic acid (reduced form), luminol, hydrogen peroxide $\left(\mathrm{H}_{2} \mathrm{O}_{2}\right)$, cobalt chloride $\left(\mathrm{CoCl}_{2}\right)$, sodium hypochlorite $(\mathrm{NaClO})$, amino acids, and Tris (hydroxymethyl) aminomethane (Tris$\mathrm{HCl}$ ) were obtained from Sigma-Aldrich (St. Louis, MO, USA). Vitamin $\mathrm{C}$ tablets were purchased from BY-HEALTH Co., Ltd. (Zhuhai, China). A $10^{-2} \mathrm{~mol} \mathrm{~L}^{-1}$ luminol solution was prepared

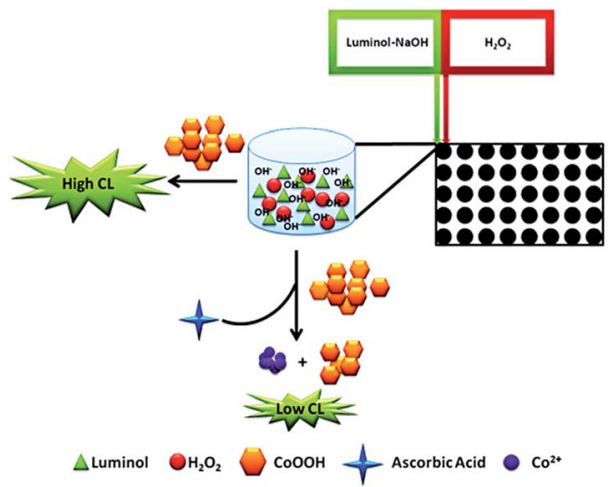

Scheme 1 Schematic illustration for AA detection by using $\mathrm{CoOOH}$ enhanced luminol $-\mathrm{H}_{2} \mathrm{O}_{2} \mathrm{CL}$ system.

by dissolving $177.1 \mathrm{mg}$ of luminol in $100 \mathrm{~mL}$ of $0.1 \mathrm{~mol} \mathrm{~L}^{-1}$ $\mathrm{NaOH}$ solution and stocked at $4{ }^{\circ} \mathrm{C}$. A stock solution of $5 \times$ $10^{-2} \mathrm{~mol} \mathrm{~L}^{-1} \mathrm{H}_{2} \mathrm{O}_{2}$ was prepared by diluting $1.5 \mathrm{~mL}$ of $30 \%(\mathrm{v} / \mathrm{v})$ $\mathrm{H}_{2} \mathrm{O}_{2}$ to $13.5 \mathrm{~mL}$ with ultrapure water. Standard solutions of ascorbic acid were prepared daily in ultrapure water. All other reagents were analytical grade without further treatment and purchased from Aladdin reagent Co., Ltd. (Shanghai, China). All solutions were prepared using ultrapure water generated from an ELGA Labwater system (US) with an electrical resistance $\geq$ 18.2 M $\Omega$. Morphology images of $\mathrm{CoOOH}$ nanosheets were photographed by transmission electron microscope (JEOL 2100 plus, Japan) at an accelerating voltage of $200 \mathrm{kV}$. A drop of sample solution was placed on a copper grid that was let to dry before being transferred into the TEM sample chamber. Fourier Transform Infrared Spectrometer (FTIR) results were tested on the IRAffinity-1 (SHIMADZU, Japan). Chemiluminescence was measured on the Spark 10M Microplate Reader (Bio-Tek, Winooski, VT). The UV-vis absorption spectra were collected on a Cary 60 UV-vis spectrometer (Agilent Technologies, USA). The crystal structure was identified by XRD-6100 (SHIMADZU, Japan). Zeta-sizer Nano (Malvern) was used to measure hydrodynamic size and zeta potential CoOOH-nanosheets. All the $\mathrm{pH}$ was performed with a Leici PHS-3C meter (Leici, Shanghai, China).

\section{Preparation of CoOOH nanosheets}

$\mathrm{CoOOH}$ nanosheets were synthesized by following the previous articles with slight modifications. ${ }^{23}$ In brief, $3 \mathrm{~mL}$ of $\mathrm{NaOH}$ $\left(1 \mathrm{~mol} \mathrm{~L}^{-1}\right)$ was added to $20 \mathrm{~mL}$ of $\mathrm{CoCl}_{2}\left(5 \mathrm{mmol} \mathrm{L}^{-1}\right)$ solution, subsequently, sonicated for $1 \mathrm{~min}$. Then, $500 \mu \mathrm{L}$ of $\mathrm{NaClO}$ $\left(0.9 \mathrm{~mol} \mathrm{~L}^{-1}\right)$ was added to the mixture and sonicated for $10 \mathrm{~min}$. After that the product was collected by centrifugation at $10619 \times g$ for $15 \mathrm{~min}$, washed with ultrapure water for three times and freeze drying for $12 \mathrm{~h}$. Finally, the power of $\mathrm{CoOOH}$ nanosheets was redispersed in ultrapure water with the aid of ultrasonic.

\section{CL measurements of AA}

The chemiluminescence sensing of AA were all performed in Tris-HCl buffer (10 mmol L $\left.{ }^{-1}, \mathrm{pH} 9.5\right)$. Typically, $250 \mathrm{ng} \mathrm{\textrm {mL } ^ { - 1 }}$ 
$\mathrm{CoOOH}$ nanosheets solution and ascorbic acid solutions (0-10 nmol L ${ }^{-1}$ ) were added into $130 \mu \mathrm{L}$ of $10 \mathrm{mmol} \mathrm{L}^{-1}$ Tris-HCl buffer ( $\mathrm{pH}$ 9.5) in each well of the microtiter plate. Then the pumps were washed for three times with $10^{-4} \mathrm{~mol} \mathrm{~L}^{-1}$ luminol and $0.1 \mathrm{~mol} \mathrm{~L}^{-1} \mathrm{H}_{2} \mathrm{O}_{2}$. Afterwards, luminol solution and $\mathrm{H}_{2} \mathrm{O}_{2}$ solution with the flow injection rates of $200 \mu \mathrm{L} \mathrm{s}^{-1}$ were injected into the target microtiter plate well. The specific schematic diagram of flow injection was illustrated in Scheme 1. The CL signals were monitored by PMT adjacent to the CL flow-through column. The signals were imported to the computer for data acquisition. The relative CL intensity $\left\{\left(\mathrm{CL}_{0}-\mathrm{CL}\right) / \mathrm{CL}_{0}\right\}$ was used for calibration and quantification of $\mathrm{AA}$, where $\mathrm{CL}_{0}$ and $\mathrm{CL}$ represented the $\mathrm{CL}$ intensities with and without adding $\mathrm{AA}$, respectively.

\section{Selectivity}

To investigate the selectivity of the proposed method, the response of the system to $10 \mathrm{pmol} \mathrm{L}^{-1} \mathrm{AA}$ and $100 \mathrm{pmol} \mathrm{L}^{-1}$ potential interferences which were prepared in ultrawater were tested. The interferences we tested are including twelve different kinds of amino acids (Trp, Gly, Phe, Ile, Val, Asp, Arg, Tyr, Cys, His, Leu, Lys), seven kinds of electrolytes $\left(\mathrm{ZnSO}_{4}\right.$, $\mathrm{MgSO}_{4}, \mathrm{CaCl}_{2}, \mathrm{KCl}, \mathrm{NaCl}, \mathrm{AlCl}_{3}, \mathrm{CoCl}_{2}$ ), glucose, sucrose and dopamine (DA). Subsequently, the CL intensity of the interfering species was recorded by utilizing Spark 10M Reader.

\section{Detection of AA in commercial tablets samples}

In order to study the detection performance of the method in practical applications, commercial vitamin $\mathrm{C}$ tablets were investigated. The vitamin $\mathrm{C}$ tablet was crushed in a pestle and mortar. The crushed powder $(1.0 \mathrm{~g})$ was weighed accurately and dissolved in $50 \mathrm{~mL}$ ultrapure water with ultrasonication. Then the solution was centrifuged at $10619 \times g$ for $15 \mathrm{~min}$ to remove the insoluble impurities. Afterwards, the resulting solution was diluted $10^{7}$ fold with ultrapure water to make sure the AA concentration fall into the detection range. Then $20 \mu \mathrm{L}$ AA $(200$ pmol L ${ }^{-1}, 1 \mathrm{nmol} \mathrm{L}^{-1}$, and $2 \mathrm{nmol} \mathrm{L}^{-1}$ ) was mixed with $130 \mu \mathrm{L}$ diluted tablet solutions in the appointed well of the microtiter plate, and $10 \mu \mathrm{L}$ CoOOH nanosheets $\left(2.5 \mu \mathrm{g} \mathrm{mL}^{-1}\right)$ were added. The assay conditions used were the same as mentioned above for detecting AA in vitamin tablets.

\section{Results and discussion}

\section{Preparation and characterization of $\mathrm{CoOOH}$ nanosheets}

Under the alkaline condition, $\mathrm{CoCl}_{2}$ can react with $\mathrm{NaClO}$ to form ultrathin $\mathrm{CoOOH}$ nanosheets. To investigate the morphology of the $\mathrm{CoOOH}$ nanosheets, the TEM assay was performed. As shown in Fig. 1A, the CoOOH nanosheets had the typical hexagon morphology with the particles size around 80 to $100 \mathrm{~nm}$. Simultaneously, the DLS investigated the size of the $\mathrm{CoOOH}$ nanosheets and indicated that the particle size of the prepared $\mathrm{CoOOH}$ nanosheets is uniform (Fig. 1B). The zeta potential of the $\mathrm{CoOOH}$ nanosheets was $15.02 \mathrm{mV}$, showing the positive charge of the nanosheets (Fig. S1 $\dagger$ ), which was attributed to its innovative properties of high conductivity,
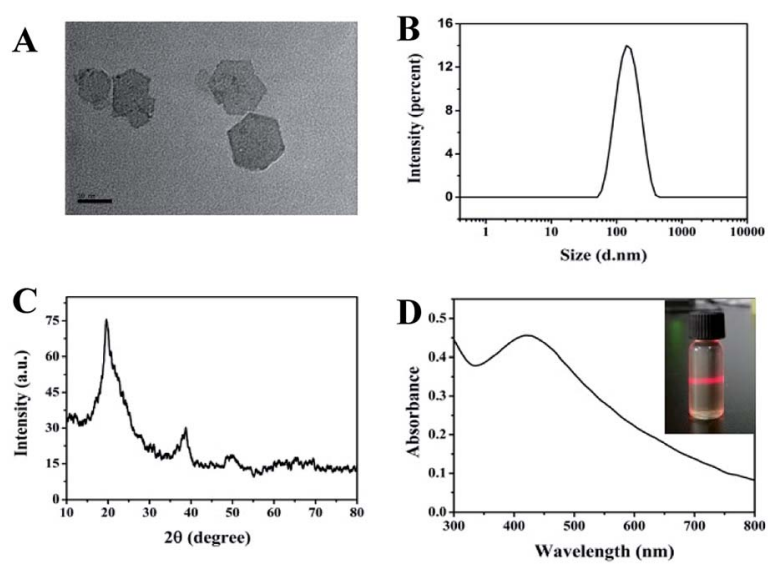

Fig. 1 (A) TEM image of $\mathrm{COOOH}$. (B) DLS measurements of $\mathrm{CoOOH}$ nanosheets. (C) XRD pattern of the $\mathrm{CoOOH}$ nanosheets. (D) UV-vis absorption spectra of $\mathrm{CoOOH}$ nanosheets (inset: the Tyndall effect of the $\mathrm{CoOOH}$ nanosheets solution).
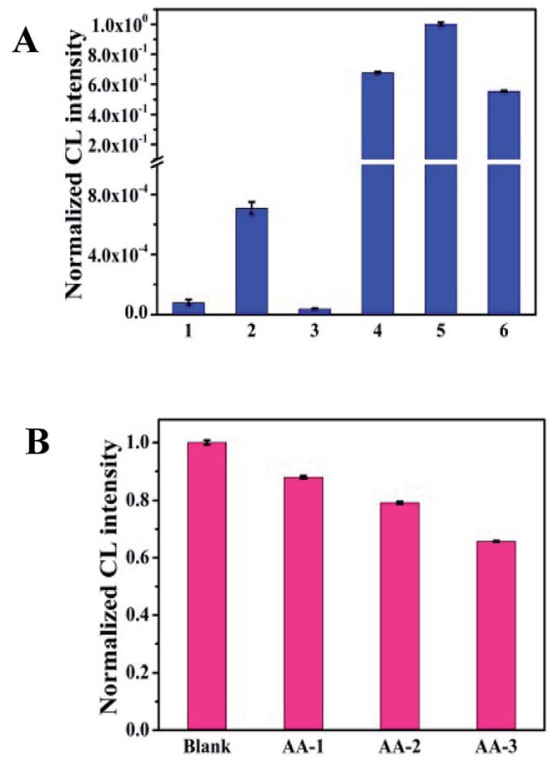

Fig. 2 (A) Effect of $\mathrm{CoOOH}$ on the $\mathrm{CL}$ intensity: luminol system; luminol $-\mathrm{H}_{2} \mathrm{O}_{2}$ system; luminol- $\mathrm{CoOOH}$ system; luminol $-\mathrm{H}_{2} \mathrm{O}_{2}-$ $\mathrm{Co}^{2+}$ (the concentration of $\mathrm{Co}^{2+}$ is $2.5 \times 10^{-7} \mathrm{~g} \mathrm{~mL}^{-1}$ ); luminol$\mathrm{H}_{2} \mathrm{O}_{2}-\mathrm{CoOOH}$ system; luminol $-\mathrm{H}_{2} \mathrm{O}_{2}-\mathrm{CoOOH}-\mathrm{AA}$ system (the concentration of $\mathrm{AA}$ is $100 \mathrm{nmol} \mathrm{L}{ }^{-1}$ ). (B) The $\mathrm{CoOOH}$ enhanced luminol $-\mathrm{H}_{2} \mathrm{O}_{2} \mathrm{CL}$ system responsed to different concentrations of $A A$ : the concentration of $A A$ is $0,10^{-12}, 10^{-11}, 10^{-10} \mathrm{~mol} \mathrm{~L}^{-1}$, respectively. Conditions: luminol: $10^{-4} \mathrm{~mol} \mathrm{~L}^{-1} ; \mathrm{H}_{2} \mathrm{O}_{2}: 10^{-2} \mathrm{~mol} \mathrm{~L}^{-1} ; \mathrm{NaOH}$ : $0.01 \mathrm{~mol} \mathrm{~L}^{-1}$; $\mathrm{CoOOH}: 2.5 \times 10^{-7} \mathrm{~g} \mathrm{~mL}^{-1} ; \mathrm{pH}$ 9.5; Tris $-\mathrm{HCl}, 10 \mathrm{mmol}$ $\mathrm{L}^{-1}$; flow velocity, pump A: $200 \mu \mathrm{L} \mathrm{s}^{-1}$; pump B: $200 \mu \mathrm{L} \mathrm{s}^{-1}$. The error bar represents standard deviation of three replicate measurements.

morphology control nature of micrometer/nanometer scale. The power XRD patterns (Fig. 1C) reveal that the crystalline nature of the prepared $\mathrm{CoOOH}$ nanosheets is hexagonal system and highly crystalline in nature without any impurities. The characteristic peaks corresponding to the rhombohedral heterogenite structure which in agreement with the standard JCPDS 07-0169. ${ }^{25}$ The UV-vis absorption spectra result of 
$\mathrm{CoOOH}$ nanosheets is showed in Fig. 1D, which has an absorption around $420 \mathrm{~nm} .^{22}$ The inserted image indicated that the $\mathrm{CoOOH}$ nanosheets solution has a good dispersibility and possess the Tyndall effect of the colloidal solution. The FTIR spectrum of $\mathrm{CoOOH}$ nanosheets (Fig. S2 $\dagger$ ) has three characteristic peaks at 3472,1622 , and 615 in the range of 4000$500 \mathrm{~cm}^{-1}$, corresponding to the bond stretching of the hydrogen-bonded hydroxyl group $(-\mathrm{OH})$, the characteristic of the Co-O double bond, and the $\mathrm{Co}-\mathrm{O}^{2-}$ complex in the oxide. ${ }^{26}$ The AFM image shows that the particle size of CoOOH nanosheets is around $100 \mathrm{~nm}$ (Fig. S3†), which is confirms the result of Fig. 1B. Therefore, all of these results suggest that our $\mathrm{CoOOH}$ nanosheets were successful prepared.

\section{The feasibility and mechanism of $\mathrm{CoOOH}$ nanosheets enhanced luminol- $\mathrm{H}_{2} \mathrm{O}_{2} \mathrm{CL}$ system to detect $\mathrm{AA}$}

In order to research the feasibility of the $\mathrm{CoOOH}$ enhanced luminol- $\mathrm{H}_{2} \mathrm{O}_{2}$ CL system, we recorded the CL intensity of the individual luminol solution, luminol- $\mathrm{H}_{2} \mathrm{O}_{2}$ system, luminol$\mathrm{CoOOH}$ system, luminol- $\mathrm{H}_{2} \mathrm{O}_{2}-\mathrm{Co}^{2+}$ system, luminol- $\mathrm{H}_{2} \mathrm{O}_{2}-$ $\mathrm{CoOOH}$, luminol- $\mathrm{H}_{2} \mathrm{O}_{2}-\mathrm{CoOOH}-\mathrm{AA}$ system respectively (Fig. 2A). The results clarified that the ultrathin CoOOH nanosheets can significantly enhance the luminescence intensity of the classic luminol- $\mathrm{H}_{2} \mathrm{O}_{2}$ system, up to about 1400-fold. At the same time, compared to $\mathrm{CoOOH}, \mathrm{Co}^{2+}$ has a relative low enhancement effect on the luminol- $\mathrm{H}_{2} \mathrm{O}_{2}$ system. From Fig. 2B we can observe that the CL intensity decreased with the increase of the concentration of AA, which can be reckoned as the luminol- $\mathrm{H}_{2} \mathrm{O}_{2}-\mathrm{CoOOH}$ system can detect AA successfully. The mechanism of luminol- $\mathrm{H}_{2} \mathrm{O}_{2}$ system has been widely explored, it is generally believed that luminol loses $\mathrm{a} \mathrm{H}^{+}$ion in alkaline solution and becomes a negatively charged group i.e. 3-aminophthalic acid ion with the oxidation of $\mathrm{H}_{2} \mathrm{O}_{2}$. The chemical energy generated in the oxidation process and was absorbed by 3 -aminophthalic acid ions in an excited state. Then the valence electrons of the oxidation state are changed from the lowest vibrational level of the first electron excited state of the single line to each of the different vibrational levels of the ground state, it will produce the maximum wavelength of $425 \mathrm{~nm}$. In order to explore the possible mechanism of the CL system, we measured the luminescence spectra of luminol- $\mathrm{H}_{2} \mathrm{O}_{2}$ and luminol- $\mathrm{H}_{2} \mathrm{O}_{2}-\mathrm{CoOOH} \mathrm{CL}$ system by fluorescence spectrometer. As shown in Fig. $\mathrm{S} 4, \dagger$ after addition of $\mathrm{CoOOH}$, the maximum wavelength of emission was still $425 \mathrm{~nm}$, indicating that the luminophore of this system is still excited 3-aminophthalate ion. Therefore, the addition of $\mathrm{CoOOH}$ nanosheets did not lead to the generation of a new luminophor for the CL system. Thus, the enhanced CL signals may due to the possible peroxidise-like activity of $\mathrm{CoOOH}$ nanosheets. In Scheme 2 we proposed the possible mechanism of the luminol- $\mathrm{H}_{2} \mathrm{O}_{2}-$ $\mathrm{CoOOH}$ CL system. Under alkaline condition, luminol can be transformed into luminol radial. It is possible that $\mathrm{CoOOH}$ nanosheets possess peroxidise-like activity could catalyze $\mathrm{H}_{2} \mathrm{O}_{2}$ to generate active intermediates such as $\mathrm{OH}^{\cdot}$ and $\mathrm{O}_{2}{ }^{-}$. . Luminol radical reacts with active intermediates yield 3 -aminophthalate anion and produce the maximum wavelength of $425 \mathrm{~nm}$. The

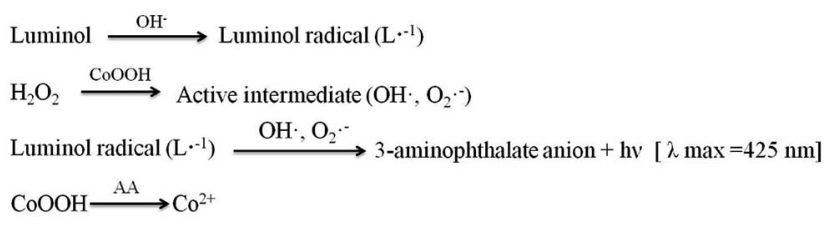

Scheme 2 Possible mechanism of luminol $-\mathrm{H}_{2} \mathrm{O}_{2}-\mathrm{CoOOH} \mathrm{CL}$ system.
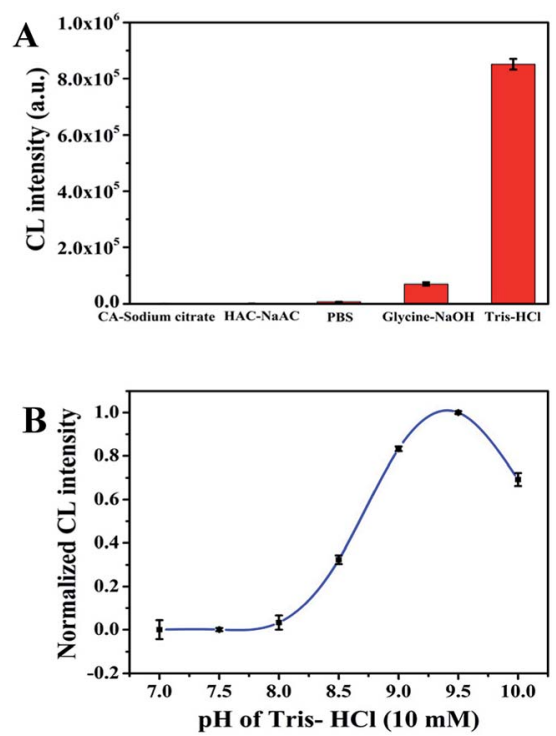

Fig. 3 The influence of reaction conditions on the $\mathrm{CL}$ intensity of the $\mathrm{CoOOH}$ enhanced luminol- $\mathrm{H}_{2} \mathrm{O}_{2} \mathrm{CL}$ system. (A) Effect of buffer solution (the concentrations of all the buffer solution are $10 \mathrm{mmol} \mathrm{L}^{-1}$ ): luminol, 10 $0^{-4} \mathrm{~mol} \mathrm{~L}-1, \mathrm{H}_{2} \mathrm{O}_{2}, 0.01 \mathrm{~mol} \mathrm{~L}{ }^{-1} ; \mathrm{pH} \mathrm{10;} \mathrm{COOOH}, 2.5 \times$ $10^{-7} \mathrm{~g} \mathrm{~mL}^{-1}$; flow velocity, pump A: $200 \mu \mathrm{L} \mathrm{s}^{-1}$; pump B: $200 \mu \mathrm{L} \mathrm{s}^{-1}$. (B) Effect of buffer $\mathrm{pH}$ : luminol, $10^{-4} \mathrm{~mol} \mathrm{~L}^{-1} ; \mathrm{H}_{2} \mathrm{O}_{2}, 0.01 \mathrm{~mol} \mathrm{~L}^{-1}$; Tris$\mathrm{HCl}, 10 \mathrm{mM}$; CoOOH, $2.5 \times 10^{-7} \mathrm{~g} \mathrm{~mL}^{-1}$; flow velocity, pump A: 200 $\mu \mathrm{Ls}^{-1}$; pump B: $200 \mu \mathrm{L} \mathrm{s}^{-1}$. The error bar represents standard deviation of three replicate measurements.

addition of AA can reduce $\mathrm{CoOOH}$ into $\mathrm{Co}^{2+}$, which inhibit the catalyze effect of transform $\mathrm{H}_{2} \mathrm{O}_{2}$ into active intermediates. The results showed in Fig. 2 demonstrated that the conventional luminol- $\mathrm{H}_{2} \mathrm{O}_{2}$ CL system based on $\mathrm{CoOOH}$ nanosheets can be successfully used to detect the concentration of AA.

\section{Optimization of experimental conditions}

To acquire credible and reliable results, we optimized different kinds of experimental conditions including the concentration of $\mathrm{H}_{2} \mathrm{O}_{2}$, the concentration of $\mathrm{CoOOH}$, the optimum buffer, the buffer $\mathrm{pH}$ and the optimal flow velocity. The experimental result showed in Fig. S5 $\dagger$ indicates that when the concentration of $\mathrm{H}_{2} \mathrm{O}_{2}$ was in the range of 0.00 to $0.1 \mathrm{~mol} \mathrm{~L}^{-1}$, the CL signal increased and reaches the maximum value while the concentration is $0.01 \mathrm{~mol} \mathrm{~L}^{-1}$, after that the $\mathrm{CL}$ signal starts to decrease. Therefore, $0.01 \mathrm{~mol} \mathrm{~L}^{-1}$ was chose as the best concentration of $\mathrm{H}_{2} \mathrm{O}_{2}$. Fig. S6 $\uparrow$ showed that the CL intensity is

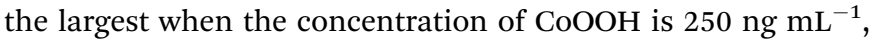
so we chose $250 \mathrm{ng} \mathrm{mL}^{-1}$ as the optimal concentration of 


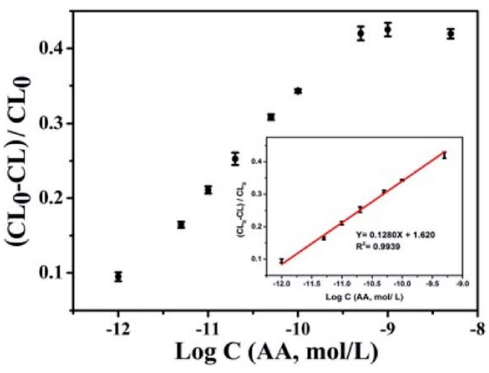

Fig. 4 Plot of relative $C L$ intensity against $A A$ concentration (inset: linear relationship between $\left(\mathrm{CL}_{0}-\mathrm{CL}\right) / \mathrm{CL}_{0}$ and log concentration of AA). Conditions: luminol, $1 \times 10^{-4} \mathrm{~mol} \mathrm{~L}^{-1} ; \mathrm{H}_{2} \mathrm{O}_{2}, 0.01 \mathrm{~mol} \mathrm{~L}{ }^{-1}$; Tris$\mathrm{HCl} 10 \mathrm{mmol} \mathrm{L}{ }^{-1} ; \mathrm{pH}$ 9.5; $\mathrm{CoOOH}, 2.5 \times 10^{-7} \mathrm{~g} \mathrm{~mL}^{-1}$; flow velocity, pump A: $200 \mu \mathrm{L} \mathrm{s}^{-1}$; pump B: $200 \mu \mathrm{L} \mathrm{s}^{-1}$. $\mathrm{CL}_{0}$ represents the $\mathrm{CL}$ intensity without $A A$, and $C L$ represents the $C L$ intensity with different concentrations of AA. The error bar represents standard deviation of three replicate measurements.

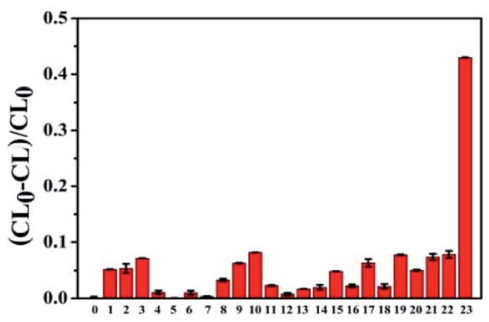

Fig. 5 Relative $\mathrm{CL}$ intensity of $\mathrm{CoOOH}$ enhanced luminol- $\mathrm{H}_{2} \mathrm{O}_{2} \mathrm{CL}$ system in the presence of $100 \mathrm{pmol} \mathrm{L}^{-1}$ potential interferents and 10 pmol $\mathrm{L}^{-1} \mathrm{AA}$. From left to right: blank, tryptophan, glycine, phenylalanine, isoleucine, valine, aspartic acid, arginine, tyrosine, tyrosine, histidine, leucine, lysine, glucose, sucrose, dopamine, $\mathrm{ZnSO}_{4}, \mathrm{MgSO}_{4}$, $\mathrm{CaCl}_{2}, \mathrm{KCl}, \mathrm{NaCl}, \mathrm{AlCl}_{3}, \mathrm{CoCl}_{2}, \mathrm{AA}$. Conditions: luminol, $1 \times$ $10^{-4} \mathrm{~mol} \mathrm{~L}^{-1} ; \mathrm{H}_{2} \mathrm{O}_{2}, 0.01 \mathrm{~mol} \mathrm{~L}{ }^{-1}$; Tris- $\mathrm{HCl} 10 \mathrm{mmol} \mathrm{L}^{-1} ; \mathrm{pH}$ 9.5; $\mathrm{CoOOH}, 2.5 \times 10^{-7} \mathrm{~g} \mathrm{~mL}^{-1}$; flow velocity, pump A: $200 \mu \mathrm{L} \mathrm{s}^{-1}$; pump B: $200 \mu \mathrm{L} \mathrm{s}^{-1}$. The error bar represents standard deviation of three replicate measurements.

$\mathrm{CoOOH}$. In order to investigate the effect of buffer on the system CL intensity we chose five different kinds of buffer solutions, we can observed from Fig. 3A that while the buffer is Tris- $\mathrm{HCl}$ the CL signal is the highest, so we chose Tris- $\mathrm{HCl}$ as the appropriate buffer for the CL system. We also investigated the $\mathrm{pH}$ of buffer, Fig. 3B illustrated that when the Tris- $\mathrm{HCl}$ buffer is 9.5 the CL intensity is the highest. Thus, 9.5 was chosen as the optimal $\mathrm{pH}$ in the following experiments. As for the flow velocity, we can observe from Fig. $\mathrm{S} 7 \dagger$ that there is no significant variation of $\mathrm{CL}$ intensity between different flow rates. As a result, we finally chose the default value (pump A: $200 \mu \mathrm{L} \mathrm{s}^{-1}$; pump B: $200 \mu \mathrm{L} \mathrm{s}^{-1}$ ) as the optimal flow velocity for the followup experiments.

\section{Detection of ascorbic acid based on $\mathrm{CoOOH}$ nanosheets enhanced luminol- $\mathrm{H}_{2} \mathrm{O}_{2} \mathrm{CL}$ system}

In order to ascertain the application of the CL system to quantify ascorbic acid, under the optimal experimental conditions we measured the $\mathrm{CL}$ response of $\mathrm{CoOOH}$ enhanced luminol- $\mathrm{H}_{2} \mathrm{O}_{2}$ system after reaction with ascorbic acid. Fig. 4 shows the relative CL intensity against AA concentration, we observed that when the concentration of AA attains to $500 \mathrm{pmol}$ $\mathrm{L}^{-1}$ the $\mathrm{CL}$ intensity intended to be steady, which means the sensing recovery reached the maximum. Moreover, a good linear relationship between $\left(\mathrm{CL}_{0}-\mathrm{CL}\right) / \mathrm{CL}_{0}$ and AA concentration which ranging from $1 \mathrm{pmol} \mathrm{L}^{-1}$ to $500 \mathrm{pmol} \mathrm{L}^{-1}$ with a correlation coefficient square of 0.9939 was obtained (inset in Fig. 4), where $\mathrm{CL}_{0}$ and $\mathrm{CL}$ represented the absence and presence of AA, respectively. In addition, we also describe a comparison about the performance of this approach with previously recommended methods for AA determination in ESI Table S1. $\dagger$ The result indicates that the sensitivity is higher than many previous methods. Furthermore, the $\mathrm{CoOOH}$ nanosheets enhanced luminol- $\mathrm{H}_{2} \mathrm{O}_{2}$ CL system can be applied to the determination of AA in various real samples.

\section{Selectivity of $\mathrm{CoOOH}$ nanosheets enhanced luminol- $\mathrm{H}_{2} \mathrm{O}_{2} \mathrm{CL}$ system for AA detection}

Selectivity is an important factor to evaluate the CL system for detecting AA, because of the complexity of the tested environment, multitudinous coexistent such as common amino acids, electrolytes and other biological molecules would have a negative effect on the AA detection. Several interfering substances including amino acids (Trp, Gly, Phe, Ile, Val, Asp, Arg, Tyr, Cys, His, Leu, Lys), electrolytes $\left(\mathrm{ZnSO}_{4}, \mathrm{MgSO}_{4}, \mathrm{CaCl}_{2}, \mathrm{KCl}, \mathrm{NaCl}\right.$, $\mathrm{AlCl}_{3}, \mathrm{CoCl}_{2}$ ) and some small biomolecules (glucose, sucrose and dopamine) were assessed under the optimal experimental conditions. As shown in Fig. 5, whether amino acids, electrolytes or small biological molecules do not generate an obvious and apparent interference on the proposed luminescence system even though the concentration of these interferents is 10 fold higher than that of AA. Therefore, this CL system based on $\mathrm{CoOOH}$ nanosheets could be applied for detecting AA in medicinal tablets or food samples directly.

\section{Detection of ascorbic acid in commercial tablets}

In order to explore the feasibility of this proposed procedure in complicated real sample environment, the assay was then

Table 1 Analytical results of determination of ascorbic acid in medicinal tablets samples

\begin{tabular}{|c|c|c|c|c|c|c|}
\hline 1 & 241.9 & 235.7 & 20 & 254.7 & 95.0 & 1.29 \\
\hline 3 & & & 200 & 428.5 & 96.4 & 1.44 \\
\hline
\end{tabular}


applied to detect AA spiked in diluted medical tablets. The tablets were dissolved, diluted and then spiked into three different kinds of concentration of AA. The content of AA in tablets was determined by this proposed method. As shown in Table 1, the recoveries of the spiked amounts of AA in diluted medical tablets solutions were obtained in the range of 95.098.6\% with relative standard deviations (RSDs) below $1.56 \%$ for the real sample. These results proved that this CL sensing system based on $\mathrm{CoOOH}$ nanosheets-luminol- $\mathrm{H}_{2} \mathrm{O}_{2}$ was likely to be capable of real sample analysis.

\section{Conclusions}

In this work, the ultrathin $\mathrm{CoOOH}$ nanosheets were firstly found which hold the ability of enchancing the chemiluminescence performance of the conventional luminol- $\mathrm{H}_{2} \mathrm{O}_{2}$ system. The enhanced CL ability was ascribed to the possible peroxidise-like activity of $\mathrm{CoOOH}$ nanosheets. Based on this principle, this method shows strong detection ability for AA with ultrasensitivity and good selectivity. Meanwhile, this assay could not only function in aqueous solution for AA detection but also exhibit reliable responses toward AA in real samples. Taking full advantages of $\mathrm{CoOOH}$ nanosheets-luminol- $\mathrm{H}_{2} \mathrm{O}_{2}$ CL system, this assay shows remarkable properties including ultrasensitive, fast, simple, and cost-effective as well as environmental-friendly, which suggest that this strategy has a great potential to be utilized as an efficient tool for determination of AA level in biological environments.

\section{Conflicts of interest}

There are no conflicts to declare.

\section{Acknowledgements}

This work was supported in part by the National Natural Science Foundation of China (21205108, 21705036), the Foundation for University Key Teacher by Henan Province (2017GGJS007) and Fundamental Research Funds for the Central Universities from Hunan University.

\section{References}

1 Z. Gazdik, O. Zitka, J. Petrlova, et al. Determination of vitamin $\mathrm{C}$ (ascorbic acid) using high performance liquid chromatography coupled with electrochemical detection, Sensors, 2008, 8, 7097-7112.

2 Y. Hu, L. Zhang, X. Geng, et al. A rapid and sensitive turn-on fluorescent probe for ascorbic acid detection based on carbon dots- $\mathrm{MnO}_{2}$ nanocomposites, Anal. Methods, 2017, 9, 5653-5658.

3 J. Velíšek and K. Cejpek, Biosynthesis of food constituents: Vitamins 2. water-soluble vitamins: part 1-A review, Czech J. Food Sci., 2007, 25, 49-64.

4 J. Liu, Z. Chen, D. Tang, et al. Graphene quantum dots-based fluorescent probe for turn-on sensing of ascorbic acid, Sens. Actuators, B, 2015, 212, 214-219.
5 X. Wang, P. Wu, X. Hou, et al. An ascorbic acid sensor based on protein-modified Au nanoclusters, Analyst, 2013, 138, 229-233.

6 H. Meng, X. Zhang, C. Yang, et al. Efficient two-photon fluorescence nanoprobe for turn-on detection and imaging of ascorbic acid in living cells and tissues, Anal. Chem., 2016, 88, 6057-6063.

$7 \mathrm{~J}$. Lykkesfeldt, Determination of ascorbic acid and dehydroascorbic acid in biological samples by highperformance liquid chromatography using subtraction methods: reliable reduction with tris[2-carboxyethyl] phosphine hydrochloride, Anal. Biochem., 2000, 282, 89-93.

8 A. G. Frenich, M. E. H. Torres, A. B. Vega, et al. Determination of ascorbic acid and carotenoids in food commodities by liquid chromatography with mass spectrometry detection, J. Agric. Food Chem., 2005, 53, 7371-7376.

9 J. K. Kwakye, The use of stabilizers in the UV assay of ascorbic acid, Talanta, 2000, 51, 197.

10 G. Wang, Z. Chen and L. Chen, Mesoporous silica-coated gold nanorods: towards sensitive colorimetric sensing of ascorbic acid via target-induced silver overcoating, Nanoscale, 2011, 3, 1756-1759.

11 L. He, F. Wang, Y. Chen, et al. Rapid and sensitive colorimetric detection of ascorbic acid in food based on the intrinsic oxidase-like activity of $\mathrm{MnO}_{2}$ nanosheets, Luminescence, 2018, 33, 145-152.

12 S. A. Kumar, P. H. Lo and S. Chen, Electrochemical selective determination of ascorbic acid at redox active polymer modified electrode derived from direct blue 71, Biosens. Bioelectron., 2008, 24, 518-523.

13 X. Cao, L. Luo, Y. Ding, et al. Electrochemical methods for simultaneous determination of dopamine and ascorbic acid using cetylpyridine bromide/chitosan composite filmmodified glassy carbon electrode, Sens. Actuators, B, 2008, 129, 941-946.

14 S. Huang, F. Zhu, Q. Xiao, et al. A CdTe/CdS/ZnS core/shell/ shell QDs-based "OFF-ON" fluorescent biosensor for sensitive and specific determination of $\mathrm{L}$-ascorbic acid, $R S C$ Adv., 2014, 4, 46751-46761.

15 L. Zhang, G. Wang, D. Wu, et al. Highly selective and sensitive sensor based on an organic electrochemical transistor for the detection of ascorbic acid, Biosens. Bioelectron., 2018, 100, 235-241.

16 Y. Dong, T. Gao, X. Chu, et al. Flow injectionchemiluminescence determination of ascorbic acid based on luminol-ferricyanide-gold nanoparticles system, $J$. Lumin., 2014, 154, 350-355.

17 Y. Ma, M. Zhou, X. Jin, et al. Flow-injection chemiluminescence determination of ascorbic acid by use of the cerium(Iv)-Rhodamine B system, Anal. Chim. Acta, 2002, 464, 289-293.

18 Z. Zhang, H. Cui, C. Lai, et al. Gold nanoparticle-catalyzed luminol chemiluminescence and its analytical applications, Anal. Chem., 2005, 77, 3324-3329.

19 Z. Wang, X. Teng and C. Lu, Carbonate interlayered hydrotalcites-enhanced peroxynitrous acid 
chemiluminescence for high selectivity sensing of ascorbic acid, Analyst, 2012, 137, 1876-1881.

20 D. Ji, Y. Du, H. Meng, et al. A novel colorimetric strategy for sensitive and rapid sensing of ascorbic acid using cobalt oxyhydroxide nanoflakes and $3,3^{\prime}, 5,5^{\prime}$ tetramethylbenzidine, Sens. Actuators, B, 2018, 256, 512-519.

21 N. Li, Y. Li, Y. Han, et al. A highly selective and instantaneous nanoprobe for detection and imaging of ascorbic acid in living cells and in vivo, Anal. Chem., 2014, 86, 3924-3930.

22 W. Cui, Y. Wang, D. Yang, et al. Fluorometric determination of ascorbic acid by exploiting its deactivating effect on the oxidase-mimetic properties of cobalt oxyhydroxide nanosheets, Mikrochim. Acta, 2017, 184, 4749-4755.

23 J. Liu, D. Tang, Z. Chen, et al. Chemical redox modulated fluorescence of nitrogen-doped graphene quantum dots for probing the activity of alkaline phosphatase, Biosens. Bioelectron., 2017, 94, 271-277.

24 Q. Cai, J. Li, J. Ge, et al. A rapid fluorescence "switch-on" assay for glutathione detection by using carbon dots- $\mathrm{MnO}_{2}$ nanocomposites, Biosens. Bioelectron., 2015, 72, 31-36.

25 K. K. Lee, P. Y. Loh, C. H. Sow, et al. $\mathrm{CoOOH}$ nanosheet electrodes: simple fabrication for sensitive electrochemical sensing of hydrogen peroxide and hydrazine, Biosens. Bioelectron., 2013, 39, 255-260.

26 A. D. Jagadale, D. P. Dubal and C. D. Lokhande, Electrochemical behavior of potentiodynamically deposited cobalt oxyhydroxide (CoOOH) thin films for supercapacitor application, Mater. Res. Bull., 2012, 47, 672-676. 